\title{
Gall for Papers
}

\section{Management and Organization Revieze Special issue on 'The Globalization of Chinese Enterprises: Environment, Strategy and Performance'}

\author{
Guest Editors: \\ Ilan Alon, Rollins China Center, Rollins College \\ John Child, Birmingham Business School \\ Shaomin Li, Old Dominion University \\ John McIntyre, GIBER, Georgia Institute of Technology
}

Submission Deadline: May 1, 2009

The twenty-first century has been dubbed the "Chinese Century". As China becomes a dominant world economic actor, its enterprises increasingly look to distant shores in the Western Hemisphere, the European continent as well as the Crescent of Crisis. Its stateowned enterprises and nascent corporate forms are emerging onto the world stage. The academic literature has begun to explore this new internationalization phenomenon. Its size, corporate manifestations, impacts on Chinese growth, and the world economy and prospects are still not well understood.

A number of important issues need to be addressed in the process of the globalization of the Chinese firms. For example, what are the objectives of the Chinese firms that go abroad? How do they formulate and implement their strategy? How should their performance be evaluated? Going abroad imposes an array of challenges to the Chinese firms, which have not been well exposed to operating in foreign environments. Their learning experience needs to be documented and studied. From the perspective of organizational theory, we need to understand how the outbound Chinese firms design their organization, balance the headquarter-subsidiary relationship, and cope with foreign culture. Furthermore, we need to examine the interaction between the Chinese MNCs and the institutions ("game-rules") of the global marketplace. For example, what impact will the Chinese firms have on the institutions of the global marketplace? How do the global institutions affect the Chinese MNCs?

The topics envisioned for the special issue will be broad as long as they can be tied to the major themes of the globalization of Chinese firms. Appropriate topics for inclusion in the special issue could include but are not limited to:

- Objectives, strategies, and performance of Chinese firms in globalization

- Organizational design, structure, and outcome in globalization

- Dissemination of knowledge on the emergence of globalizing Chinese firms 
- The impact of Chinese business and firms on global business and environments

- The role of culture and culture change in Chinese firms in globalization

- Headquarter-subsidiary relationships in Chinese firms

- Chinese business groups/conglomerates in globalization

- Chinese family-owned firms in globalization

- Forms of engagement with foreign firms used by internationalizing Chinese firms (e.g. partnerships, acquisitions, OEM, ODM, OBM, etc.)

To date, much of the China research has been forming a foundation for understanding strategy and performance, particularly of foreign firms in China. However, there has not been very much work that examines the globalization of Chinese firms. The articles in the special issue will also make theoretical contributions in internationalization, entry mode, organizational design, cultural change, and institutional environment.

We believe that the proposed work will enhance our understanding of the globalization of Chinese firms, both empirically and theoretically and should be widely cited as scholars and practitioners seek to explain how and why Chinese firms go abroad, how they perform, and how they interact with the global environment of business.

When submitting to the special issue, please follow standard $M O R$ submission guidelines, which can be viewed at both http://www.blackwellpublishing.com/mor and http:// www.iacmr.org and are published in the first issue of every volume of $M O R$.

Please submit your paper to the lead guest editor Ilan Alon (ialon@rollins.edu) and copy it to iacmr.mor@asu.edu. Identify your paper as a submission to the special issue on The Globalization of Chinese Enterprises. Papers will be double-blind peer reviewed and acceptance decisions will be based on the standards described in the MOR mission statement. 